\title{
HISTOPATHOLOGICAL SPECTRUM OF SKIN ADNEXAL NEOPLASMS AT MAYO HOSPITAL, LAHORE
}

\author{
FAIQA SAMAN, SAFEENA SARFRAZ, MADIHA ARSHAD, SHAHIDA NIAZI, \\ QURRAT-UL-AIN TAHIR, RAHEEL AHMED \\ Department of Pathology, King Edward Medical University, Lahore, Pakistan.
}

\begin{abstract}
Objective: To find out the frequency of benign and malignant skin adnexal neoplasms.

Methods: It is a descriptive study in which we studied all cases of skin adnexal tumors that are registered in Mayo hospital over the period of six months. Tumors were evaluated according to the type and site, age, and gender of the patient. The tumors are classified by WHO classification. Data collected was analyzed using SPSS Version 21 for statistical analysis.

Results: 45 skin adnexal tumors were studied in which, 40 (88.9\%) were benign and $5(11.1 \%)$ were malignant.

Conclusion: Skin adnexal tumors are comparatively uncommon lesions. Benign neoplasms are more frequent than malignant.
\end{abstract}

Keywords: adnexal tumors of skin, benign, malignant

How to cite this article: Saman F, Sarfraz S, Arshad M, Niazi S, Tahir QUA, Ahmed R, Rehman F, Jafri A, Islam ZU, Sarfraz A . Histopathological spectrum of skin adnexal neoplasms at Mayo Hospital, Lahore. Pak Postgrad Med J

2020;31(1): 24-28

This is an Open Access article distributed under the terms of the Creative Commons Attribution License (http://creativecommons.org/licenses/by/3.0), which permits unrestricted use, distribution, and reproduction in any medium, provided the original work is properly cited.

DOI: HTTPS//DOI.ORG/10.51642/ppmj.v31i01.383

Correspondence to: Safeena Sarfraz

Consultant Pathologist,

Department of Pathology,

King Edward Medical University, Lahore, Pakistan.

Email:dr.safeenaraheel@gmail.com

\section{INTRODUCTION}

Skin adnexal tumours have considerable clinical and histopathological overlap. Skin adnexal tumours (SAT) are less common. They originate from pilosebaceous unit, eccrine or apocrine sweat gland. SATs are diagnosed by histopathological studies. The skin adnexal tumors (SATs) contain a wide variety of tumors. ${ }^{1}$ SATs are often nonspecific, nondescript flesh colored single or multiple papulo-nodular lesions with changing clinic-pathologic significance according to the type. ${ }^{2}$

Adnexal tumors are primary skin lesions that arise from pilosebaceous unit, eccrine or apocrine sweat glands. ${ }^{3}$ Most of these tumors are benign but malignant can arise. ${ }^{4}$ These tumors have a diagnostic and therapeutic challenge because they overlap histologically. ${ }^{5}$ Skin appendageal tumors were classified by $2005 \mathrm{WHO}^{6}$, classified into 4 types: tumours with differentiation towards hair follicles, sebaceous glands, eccrine or apocrine glands. ${ }^{7}$

SATs derived from pluripotent stem cells and specialized into different types under the influence of genes and vascularization. ${ }^{8}$ Some SATs shows areas of mixed differentiation as stem cells differentiate along multiple lines making the morphological classification of these tumors difficult. ${ }^{9}$ Because of the similarity in gross appearance, most of the time it was very difficult to evaluate the types of these tumors. ${ }^{10}$ When there is problem in classifying adnexal tumors depending on clinical grounds are labeled as "troublesome tumors". ${ }^{11}$

Most of benign tumors are flat surfaced, abscess or lumps of the same colour as patients skin or darker. Malignant tumors are rare compared to benign counterparts and irregularly shaped, and ulcerated. ${ }^{12}$ Adnexal neoplasms of low cytological degree give better prognosis if lesion is totally removed. Those with high cytological degree may 
show metastasis and exhibit more aggressive clinical course. ${ }^{13}$

Most SAT are benign, and can be eradicate by local surgical removal. ${ }^{14}$ Trichilemmomas in Cowden disease and sebaceous tumours in Muir-Torre syndrome posses important implications in the diagnosis of these tumors. ${ }^{15}$ Cutaneous cancers are more frequent in organ transplant recipients as compared to immunucompetent individuals, immunosuppressed drugs in organ transplant, rheumatoid or inflammatory diseases. ${ }^{16-17}$ Increase in number of immunocompromised people by infection HIV are also the major cause of cancer. ${ }^{18}$

New cases of dermal tumours has increased dramatically in the previous ten years as a result of increasing skin exposure..$^{19}$ A research of 66 cases of SAT were carried at India in 2016, in which 62 are benign and 4 are malignant. Benign tumors comprises tumors with hair follicle differentiation then by tumours having sebaceous differentiation; lesions with eccrine differentiation and tumours with apocrine differentiation. There were 2 cases each of sebaceous carcinoma and malignant mixed adnexal carcinoma. ${ }^{20}$

In this research we will try to evaluate the frequency of benign and malignant skin adnexal tumors, their clinical manifestation and average frequency in terms of gender and age in our surgical pathology laboratory.

\section{METHODS}

Data was collected from the skin biopsy specimens submitted to King Edward Medical University, pathology department, by non-probability, convenient sampling. A total of 45 cases were studied during the period of six months. Patient undergoing histopathology of biobpsy were enrolled in this study. The biopsies received, fixed in the formalin, processed and then slides were stained with H\&E stain. Histological examination was carried out by a consultant histopathologist under light microscope. Data was collected using pre-designed pro-forma which covers various aspects of all the processes involved from specimen requisition till dispatch of final report. Sample size of 45 patients is estimated by using $95 \%$ confidence level, $7 \%$ absolute precision with expected \%age of benign tumors constituting as $93.94 \%$.

Collected data was entered by using Statistical package for social sciences (SPSS version 21). Quantitative variables like age will be presented as mean \pm S.D. Qualitative variables like type of neoplasms, gender and site of tumor will be presented as frequency and percentage.

Inclusion Criteria: All cases of skin biopsies submitted to pathology laboratory. Age and gender both male and female.

Exclusion Criteria: Autolyzed sample. Patients already on chemotherapy or radiotherapy.

\section{RESULTS}

To evaluate the frequency of benign and malignant skin adnexal tumors, a total of 45 skin adnexal tumors coming to our pathology laboratory were diagnosed during the study period. Benign Adnexal Tumors constituted the majority of tumors with 40 out of 45 cases $(88.9 \%)$ while only $05(11.1 \%)$ malignant Adnexal Tumors were encountered. Sweat gland lesions accounted for the biggest number of cases $44.4 \%$ (21/45), followed by hair follicle tumors $31.1 \%$ (14/45) and sebaceous gland tumors $22.2 \%(10 / 45)$. There was no striking sex difference. The male $51.1 \%$ (23/45) -to-female $48.9 \%$ (22/45) ratio was approximately equal.

The maximum frequency was seen in $26-50$ years (17/45) followed by age groups of 51-75(16/45), <25 $(10 / 45)$ years and $>75(2 / 45)$ years respectively. (Table 1$)$ According to the site of distribution, the most common site, head and neck region, accounting for $63.6 \%$ of the cases followed by extremities $(22.6 \%)$ and trunk (13.6\%).

Table 1. Age wise distribution of skin adnexal tumors

\begin{tabular}{cc}
\hline Age groups & Number of cases \\
\hline$<25$ & 10 \\
$26-50$ & 17 \\
$51-75$ & 16 \\
$>75$ & 2 \\
Total & 45 \\
\hline
\end{tabular}

Table 2. The site and sex distribution of observed adnexal tumors

\begin{tabular}{lcccc}
\hline Site of tumor & Male & Female & Total & $\begin{array}{l}\text { Percentage } \\
\text { incidence }\end{array}$ \\
\hline Head and Neck & & & & \\
Scalp & 2 & - & 2 & 4.44 \\
Face & 9 & 16 & 25 & 55.56 \\
Neck & - & 1 & 1 & 2.22 \\
Trunk & 2 & - & 2 & 4.44 \\
Upper limb & 3 & 3 & 6 & 13.34 \\
Lower limb & 6 & 2 & 8 & 17.78 \\
Not mentioned & 1 & - & 1 & 2.22 \\
Total & 23 & 22 & 45 & 100 \\
\hline
\end{tabular}

Tumors with eccrine gland differentiation comprised of major $20(44.4 \%)$ cases. All the cases were of benign origin. The most common tumor in this category was chondroid syringoma which consists of 9 cases (20\%), followed by eccrine acrospiroma $7(15.6 \%)$. And the least frequent were eccrine poroma $2(4.4 \%)$ and eccrine spiradenoma 2(4.4\%). (Table 2).

Second most common tumor was of follicular origin $14(31.1 \%)$. The most common tumor in this category was trichoepithelioma $9(20.0 \%)$ followed by pilomatrixoma 5 $(11.1 \%)$. Tumor with sebaceous differentiation constituted 
$10(22.2 \%)$ cases (Table 1). Out of which, $05(11.1 \%)$ were benign i.e. sebaceous adenoma constituted $4(8.9 \%)$ cases followed by sebaceous hyperplasia with only 1
$(2.2 \%)$ case. $05(11.1 \%)$ were malignant i.e. sebaceous carcinoma (Table 1).

Tumor with apocrine differentiation constituted only $1(2.2 \%)$ case of apocrine hydrocystoma. (Table 1 )

Table 3: Frequency of benign and malignant skin adnexal tumors

\begin{tabular}{|c|c|c|c|c|}
\hline Types of tumor & Benign & Malignant & Frequency & Percentage (\%) \\
\hline \multirow{2}{*}{ Hair follicle } & Trichoepithelioma & & 9 & 20 \\
\hline & Pilomatrixoma & & 5 & 11.1 \\
\hline \multirow{4}{*}{ Eccrine gland } & Chondriod syringoma & & 9 & 20 \\
\hline & Eccrine poroma & & 2 & 4.4 \\
\hline & Eccrine acrospiroma & & 7 & 15.6 \\
\hline & Eccrine spiradenoma & & 2 & 4.4 \\
\hline Apocrine gland & Apocrine hydrocystoma & & 1 & 2.2 \\
\hline \multirow{3}{*}{ Sebaceous gland } & Sebaceous adenoma & & 4 & 8.9 \\
\hline & & Sebaceous carcinoma & 5 & 11.1 \\
\hline & sebaceous hyperplasia & & 1 & 2.2 \\
\hline
\end{tabular}

Figure A: Trichoepithelioma with basaloid cells

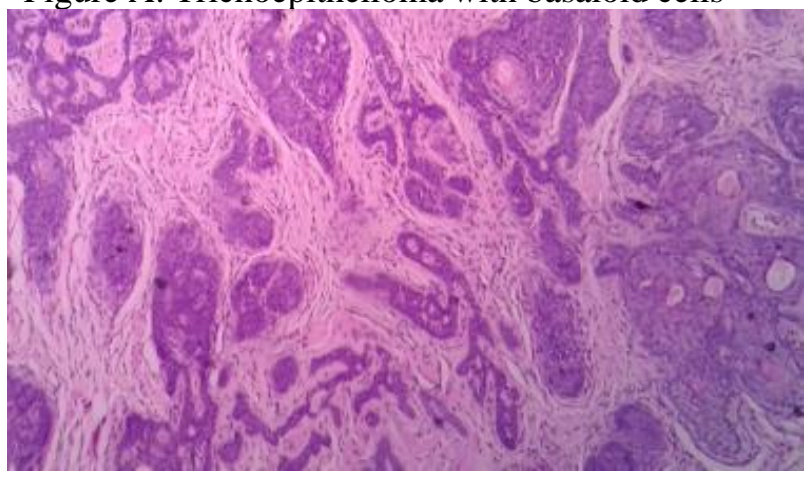

Figure B: Pilomatrixoma with shadow cells

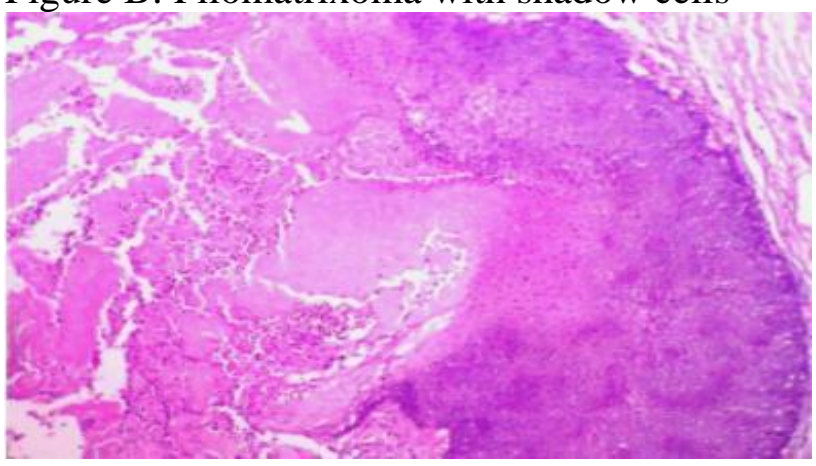

\section{DISCUSSION}

A research showed benign tumors of skin adnexa and of basal cell epithelioma by LEVER recommended that greater part of adnexal tumors emerge from essential epithelial germ and a couple of others from eccrine. ${ }^{21}$ Cutaneous adnexal tumors are derived from pluripotent cells that differentiate towards any of the lineage. ${ }^{22}$ The $\log$ duration of the tumor and the presentation as asymptomatic papule or nodule indicate the benign nature of majority of skin adnexal tumors. ${ }^{23}$
Figure C: chondroid syringoma with chondroid

Stroma and nest of polygonal cells

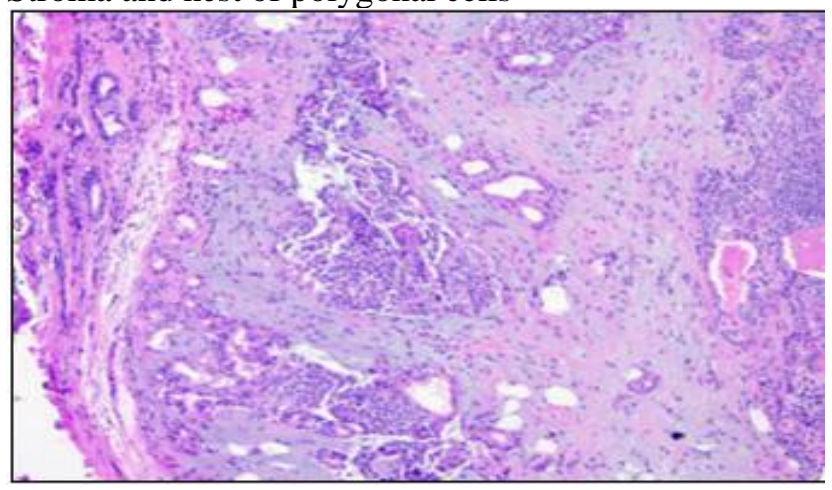

Figure D: sebaceous carcinoma: hyperchromatic

Atypical basaloid Cells with mitotic activity

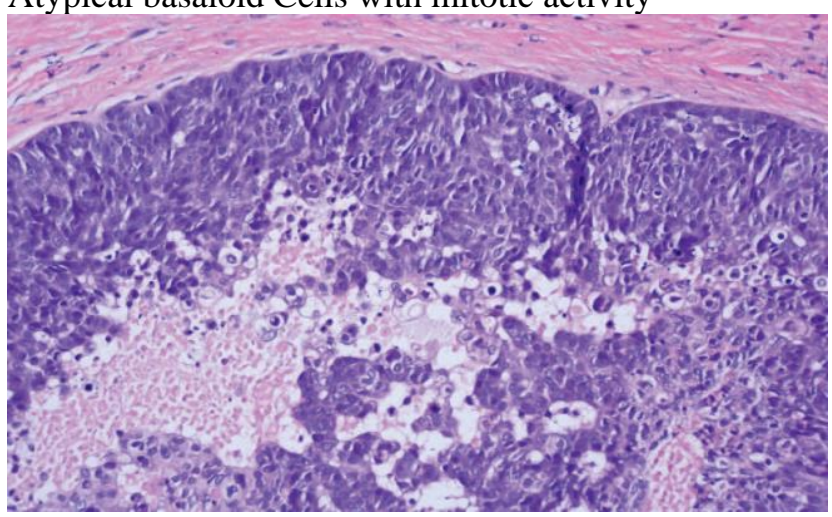

Benign tumors are more common as compared to malignant ${ }^{24}$, the findings were consistent with other studies. The percentage of benign tumors in our study was $88.9 \%$ \& $11.1 \%$ was malignant. In a study done by Pujani $\mathrm{M}$ et al. $96 \%$ were benign and only $4 \%$ cases were malignant. In a study by Nirali Amin et al. $98 \%$ tumors were benign and $2 \%$ were malignant. Similalry a study by 
Muktanjali Deka el at. $73.92 \%$ cases were benign and $26.08 \%$ cases were malignant.

According to the age, In our study the commonest year group was 26-50 years, which coincides with the studies of Nirali Amin et al. (31-40), Pujani M et al. (2140) and Muktanjali Deka el at. (41-50) years. Male Female ratio was found to be $0.92: 1$ by Pujani $\mathrm{M}$ et al. In this study, the male:female ratio was 23.22. In Muktanjali Deka et al. study female was more numerous than the male 1:3.53 which was in concordance with Nirali Amin et al. $1: 1.27$.

Nirali Amin et al., Muktanjali Deka et al. and Pujani $\mathrm{M}$ observed the head and neck being the most common region then extremities, which coincides with this our study (62.22\%). The predominance of ATs in the head and neck is a well- documented fact supported by most of the studies. This is because this region is rich in pilosebaceous units, apocrine as swell as eccrine glands. ${ }^{1,24}$

The commonest line of differentiation in our study was sweat gland (44.4\%) followed by follicular differentiation $(22.2 \%)$ and the least frequent being sebaceous gland differentiation (11.1\%).These observations are in concordance with that of Pujani $\mathrm{M}$ et al. and Nirali et al. On the contrary, Muktanjali Deka et al. found the hair follicle tumors to be the most common type. The most common tumor found was trichoepithelioma (9/45) 20\% and chondriod syringoma (9/45) 20\% followed by eccrine acrospiroma (7/45) $15.6 \%$ and pilomatrixoma $(5 / 45) 11.1 \%$. While in the studies carried out by Muktanjali Deka et al. and Nirali Amin et al. Nodular hidradenoma was the most diagnosed tumor, followed by pilomatrixoma and trichemmal cyst was the most common tumor.in the study of Muktanjali Deka et al and chondriod syringoma in case of Nirali Amin et al. While in case of Pujani $\mathrm{M}$ et al., the most common tumor encountered was hidradenoma papilliferum and pilomatrixoma.

In this study, 5/9 cases of trichoepithelioma were seen around the eyelid. Trichoepithelioma was diagnosed as BCC in our study. Histologically examination of the section reveals lesion composed of basaloid cells arranged in clusters and nests with peripheral palisading of the cells in these cells. (Figure A)

Pilomatricoma is a benign tumor, mostly occur in kids and young people; more commonly seen in females. We found $5 / 45$ cases of pilomatrixoma contain keratinized ghost cells and basaloid cells. (Figure B) Abrupt keratinization and calcification are also seen.

Syringomas, histologically, are nests, cord and small cyst. Chondriod syringoma also known as mixed tumor of the skin, represents an adenoma of intra-epidermal eccrine ducts. Histological examination of the section reveals a tumor composed of variable sized nodules present in dermis. The individual cells are smaller in size with little cytoplasm and are arranged in tubules and nests with some areas showing trabecular pattern and comma shaped configurations. (Figure C)

There were 7/45 cases of eccrine acrospiroma and $2 / 45$ cases of eccrine poroma. Poroma is a type of acrospiroma that present as a nodule usually seen on the sole or side of the foot.

Histologically, the section reveals skin covered tissue with a circumscribed encapsulated lesion in the dermis with nodular configuration. The cells are forming sheets and arranged around spaces. The cells have moderate amount of eosinophilic to clear cytoplasm and bland nuclei. The only malignant tumor encountered in our study was sebaceous carcinoma 5/45. It occurs more frequently on the eyelids as seen in our study. Histologically, sebaceous carcinoma contain a mass of basaloid cells and clusters of atypical cells with clear to eosinophilic cytoplasm and hyperchromatic, pleomorphic nuclei and high mitotic activity. (Figure D)

\section{CONCLUSION}

Skin adnexal tumors are uncommon. Benign adnexal neoplasm occurs more frequently as compared to malignant. The most frequent site of tumor was found to be head and neck region followed by extremities. The mean age was 45.86. There was no male to female predominance. Tumors of sweat gland origin were more common followed by follicle and the least frequent being sebaceous gland. Among the malignant neoplasm, sebaceous carcinoma was the most common.

\section{ETHICAL APPROVAL}

The study was approved from Ethical Review Committee of King Edward Medical University, Lahore, Pakistan, vide reference No. 2003/RC/KEMU dated September 23, 2019.

\section{REFERENCES}

1. Alam S, Lateefa M, Mohanty R. Histopathological study of 26 rare skin adnexal tumours over 5 years-a diagnostic dilemma. Int J Med Sci Public Health. 2016;5:1995-1998.

2. Jain P, Jain SK, Singh A, Goel S, Khichi SK, Goyal P. Clinico-pathological study of skin appendageal tumours from northern India. International Journal of Research in Medical Sciences. 2016;4(5):1620.

3. Sigamani K, Thukkaram C, Harke A. Clinicopathological study of skin adnexal tumours in a tertiary care hospital. Journal Of Evolution of Medical and Dental Sciences-Jemds. 2016;5(47):3117-3120.

4. Amin N, Shah S, Prajapati S, Goswami H. Histomorphological spectrum of skin adnexal tumors at a tertiary care hospital-a retrospective study. International Journal of Current Research and Review. 2016;8(4):13. 
5. Marenda S, Otto RA. Adnexal carcinomas of the skin. Otolaryngologic clinics of North America. 1993;26(1):87-116.

6. Blake PW, Bradford PT, Devesa SS, Toro JR. Cutaneous appendageal carcinoma incidence and survival patterns in the United States: a population-based study. Archives of dermatology. 2010;146(6):625-632.

7. Perez MD, Landeras R, Agromayor EG, Vela MdCG, Trino E, Martinez BG, et al. Skin adnexal lesions: Ultrasonographic features and histopathological correlation. 2016: European Congress of Radiology 2016.

8. Gandhi R, Srinivasan S. A Morphologic Study of Cutaneous Adnexal Tumours. National Journal of Laboratory Medicine. 2016.

9. Kanth GK, Vijayasree V, Madhavi M, Rao T, Narayana V. A histopathological spectrum of skin adnexal tumors. IOSR J Dent Med Sci. 2015;14:90-92.

10. Narhire V, Swami S, Baste B, Khadase S, D'costa G. A Clinicopathological study of skin and adnexal neoplasms at a rural based tertiary teaching hospital. Asian Pacific Journal of Health Sciences. 2016;3(2):153-162.

11. Cotton D. Troublesome tumours. 1: Adnexal tumours of the skin. Journal of clinical pathology. 1991;44(7):543.

12. Vijayan P, Nayak R, Ilias LM, Ponniah A. Spectrum of malignant skin adnexal tumors-a single institution study of 17 cases with clinicopathological correlation. International Journal of Research in Medical Sciences. 2015;3(8):1889.

13. Sudhakar G, Koteswari M. Skin adnexal tumors-a five years study in a tertiary care hospital. International Journal of Scientific Research. 2019;8(1).

14. Venugopal S, Madhu C, Kamath A. Malignant adnexal tumors: a rare case of cutaneous malignancy. International Surgery Journal. 2017;4(5):1786-1788.

15. Alsaad KO, Obaidat NA, Ghazarian D. Skin adnexal neoplasms - part 1: an approach to tumours of the pilosebaceous unit. Journal of clinical pathology. 2007;60(2):129-144.

16. Fueston JC, Gloster HM, Mutasim DF. Primary cutaneous adenoid cystic carcinoma: a case report and literature review. Cutis-New York-. 2006;77(3):157.
17. Harwood CA, McGregor JM, Swale VJ, Proby CM, Leigh IM, Newton R, et al. High frequency and diversity of cutaneous appendageal tumors in organ transplant recipients. Journal of the American Academy of Dermatology. 2003;48(3):401-408.

18. Engels EA, Biggar RJ, Hall HI, Cross H, Crutchfield A, Finch JL, et al. Cancer risk in people infected with human immunodeficiency virus in the United States. International journal of cancer. 2008;123(1):187-194.

19. Nair PS. A clinicopathologic study of skin appendageal tumors. Indian Journal of Dermatology, Venereology, and Leprology. 2008;74(5):550.

20. Suri J, Gupta D, Koul K, Kumari R. A Clinicopathological Analysis of Skin Adnexal Tumours: Four Year Retrospective Study. JK Science. 2016;18(4):248-251.

21. Lever WF. Pathogenesis of benign tumors of cutaneous appendages and of basal cell epithelioma: I. Benign tumors of the cutaneous appendages. Archives of dermatology and syphilology. 1948;57(4):679-708.

22. Sharma A, Paricharak DG, Nigam JS, Rewri S, Soni PB, Omhare A, et al. Histopathological Study of Skin Adnexal Tumours-Institutional Study in South India. Journal of skin cancer. 2014;2014.

23. Kamyab-Hesari K, Balighi K, Afshar N, Aghazadeh N, Rahbar Z, Seraj M, et al. Clinicopathological study of 1016 consecutive adnexal skin tumors. Acta Medica Iranica. 2013:879-885.

24. Radhika K, Phaneendra B, Rukmangadha N, Reddy M. A study of biopsy confirmed skin adnexal tumors: experience at a tertiary care teaching hospital. J Clin Sci Res. 2013;2(1):132-138.

\section{AUTHORS' CONTRIBUTION:}

FS: Conceived, designed, manuscript writing

SS, SN: Correction in manuscript

MA: Manuscript writing

QUAT: Data collection

RA: Data collection, Proof reading 